\title{
Severe Maternal Morbidity and Near Miss Mortality - A Case Report of an Adolescent with a Thyroid Storm
}

\author{
Tinuade Oyebode ${ }^{1,}$,, Bose Toma ${ }^{2}$, Henry Embu ${ }^{3}$, Fabian Puepet ${ }^{4}$, Atiene Sagay $^{1}$ \\ ${ }^{1}$ Department of Obstetrics and Gynaecology, Jos University Teaching Hospital, University of Jos, Jos, Nigeria \\ ${ }^{2}$ Department of Paediatrics, Jos University Teaching Hospital, University of Jos, Jos, Nigeria \\ ${ }^{3}$ Department of Anaesthesia, Jos University Teaching Hospital, University of Jos, Jos, Nigeria \\ ${ }^{4}$ Department of Internal Medicine (Endocrinology Unit), Jos University Teaching Hospital, University of Jos, Jos, Nigeria
}

\section{Email address:}

tinuadeoyebode@yahoo.com (Tinuade Oyebode), gabosetoma@gmail.com (Bose Toma), embuy@yahoo.com (Henry Embu), puepetfh@yahoo.co.uk (Fabian Puepet), atsagay58@yahoo.com (Atiene Sagay)

\section{To cite this article:}

Oyebode Tinuade, Toma Bose, Henry Embu, Fabian Puepet, Sagay Atiene. Severe Maternal Morbidity and Near Miss Mortality - A Case Report of an Adolescent with a Thyroid Storm. Journal of Gynecology and Obstetrics. Vol. 3, No. 4, 2015, pp. 83-87. doi: $10.11648 /$ j.jgo.20150304.13

\begin{abstract}
A thyroid storm is a major life threatening disorder and is more complicated when it happens in an unsupported pregnant teenager where possible maternal and perinatal morbidity and mortality are additional concerns on account of medical and social issues. This patient who defaulted treatment for Graves' disease for 18 months presented with cardiovascular, central nervous system, gastrointestinal, renal and obstetric complications as a medical emergency to the Labour Ward of the Jos University Teaching Hospital (JUTH). She was in cardiac failure, had anaemia and assessed to have a thyroid storm with intrauterine foetal death. She received intensive care from a multidisciplinary team with anti-thyroid and anti-heart failure drugs, oxygen, blood transfusion, antibiotics, supportive therapy, and subsequently went into labour and had forceps delivery of a macerated foetus and very proactive management that led to the aversion of a potential maternal mortality.
\end{abstract}

Keywords: Thyroid Storm, Teenage Pregnancy, Cardiac Failure, Near Miss, Maternal Mortality, Perinatal Mortality

\section{Introduction}

Thyroid function derangements are not common in pregnancy, considering that both of hypo and hyper thyroidism are associated most of the time with infertility. However Grave's disease is the commonest cause of hyper secretion of the thyroid gland, being responsible in $95 \%$ of cases $^{1}$. Cardiac disease, especially where it is associated with another severe medical condition, remains one of the nonobstetric causes of maternal mortality ${ }^{2}$.

Thyroid storm, also called thyrotoxic crisis, thyrotoxic storm, hyperthyroid storm, accelerated hyperthyroidism is very rare acute, life-threatening, hyper metabolic state induced by excessive release of thyroid hormones in individuals with thyrotoxicosis. The clinical presentation include fever, Cardiovascular abnormalities (tachycardia, palpitations, arrhythmias, hypertension, pulmonary oedema, heart failure), neurological (tremors, agitation, confusion, restlessness), urogenital system (polyuria, urinary incontinence) and gastrointestinal abnormalities (polyphagia, polydipsia, diarrhea).

Thyroid storm occurs in people with untreated hyperthyroidism and is usually brought on by a major stress like trauma, infection or pregnancy. It is almost invariably fatal if left untreated, thus rapid diagnosis and aggressive treatment are critical. ${ }^{3,4}$,

Although important strides in recognition and therapy have significantly reduced the mortality in this disorder from the nearly $100 \%$ fatality rate, survival is by no means guaranteed and fatality rates between $20 \%$ and $50 \%$ have been observed and some have attributed this improvement to relaxation of the diagnostic criteria for thyroid storm and represents improvements in early recognition and improved treatment of this disorder. Thyroid storm is a dreaded, fortunately rare complication of a very common disorder which commonly follows a precipitating event or intercurrent illness. Effective management is predicated on a prompt recognition of impending thyroid storm which is, in turn, dependent on a thorough knowledge of both the typical and atypical presentations of this disorder. A commitment to an aggressive, multifaceted therapeutic intervention is always critical to the 
obtainment of a satisfactory outcome. ${ }^{5}$

Adolescent pregnancy remains a major contribution to maternal mortality. About 16 million 15-19 years old women give birth each year, (11\% of births worldwide), and account for $23 \%$ of the overall burden of disease due to pregnancy and childbirth. Ninety-five per cent occur in low- and middle-income countries where almost $10 \%$ of girls become mothers by age 16 years. Half of all adolescent births occur in just seven countries: Bangladesh, Brazil, the Democratic Republic of the Congo, Ethiopia, India, Nigeria and the United States. ${ }^{6}$ Births to unmarried adolescent are mainly unintended and problems like infections, anaemia, HIV and others are negative outcomes of adolescent pregnancy. Stillbirths and death in the first week of life are 50\% higher among babies of adolescents as well as preterm birth, low birth weight and asphyxia causing increased perinatal morbidity and mortality. Many girls who become pregnant leave school which has long-term implications and delaying adolescent births could generate economic, social and health benefits which include less mortality. Addressing these important medical and social issues is important in forestalling maternal mortality. ${ }^{6}$

\section{Case Report}

Miss. J. S. was a 17 years old Para $0+0$ SS3 student estimated to be 32 weeks pregnant. She presented at the Labour Ward of the Jos University Teaching Hospital (JUTH) with leg swelling, difficulty in breathing, cough and palpitations of six weeks duration, three days of absent foetal movement and abdominal pain of a day. She had not received any form of antenatal care in the pregnancy. She had been diagnosed as a case of Graves' disease two years previously and had received carbimazole and propranolol for 6 months but defaulted treatment and follow up on financial grounds for 18 months despite persistence of symptoms. The symptoms had however aggravated and this was what warranted her seeking attention. There was orthopnoea, paroxysmal nocturnal dyspnea, and easy fatigability, production of frothy white sputum, palpitations and retrosternal chest pain. Symptoms were initially present on exertion but currently present at rest. There was no vaginal bleeding or rupture of membranes but she had passed mucoid and blood stained vaginal discharge. She was also experiencing increased urinary frequency but this was without dysuria. She had not registered for antenatal care during the course of the pregnancy but had presented at a private clinic in Jos because of the worsening symptoms and discomfort and had been admitted for 5 days. She was given nifedipine, lisinopril, digoxin and spironolactone but she had requested referral to JUTH considering the fact that she had been receiving care at the facility earlier. She was aware of contraception but had not used any previously.

She was first among 6 siblings being raised by their mother alone. The father had left them several years previously. She had discovered she was pregnant for a young man who was a trader in clothes, and she had moved in with him the month previously because of increasing complaints from her mother.

On Physical Examination we saw a wasted and ill looking young girl, she was very restless, in painful distress, febrile with a temperature of $37.9^{\circ} \mathrm{C}$, anicteric; pale, not cyanosed, had grade 2 finger clubbing and bilateral pedal oedema to the knees. She had bilateral exophthalmos and fine tremors at rest but there was no flappy tremor. There was a diffuse anterior neck swelling measuring $8 \times 4 \mathrm{~cm}$ that moved with deglutition. It was warm to touch and had a bruit over it.

Musculoskeletal examination revealed marked wasting. The muscles of the upper limbs, the thenar and hypothenar muscles were wasted.

On cardiovascular examination, her pulse was 128/minute, regular and bounding, the blood pressure was $180 / 120 \mathrm{~mm}$ of $\mathrm{Hg}$. The Jugular venous pressure was elevated and the precordium was hyperactive; the apex beat was in the $6^{\text {th }}$ left intercostal space, anterior axillary line. She had an apical heave, a thrill was palpated, there was a gallop rhythm and a pan-systolic murmur that radiated to the axilla.

Respiratory examination showed that she was dyspnoeic with a respiratory rate of 46 cycles per minute. She was flaring the nasi and using accessory muscles of respiration and had bilateral basal fine crepitations. She had soft, tender hepatomegaly $4 \mathrm{~cm}$ below the coastal margin on abdominal examination, but the spleen was not palpable and the kidneys were not ballotable. The symphisiofundal height was $29 \mathrm{~cm}$, she had one weak contraction in ten minutes and there was a singleton foetus, in longitudinal lie, presenting cephalic but foetal heart tones were absent. The vulva and vagina were normal, and there was blood stained mucoid discharge seen at the introitus. The cervix was soft, well effaced, central, but closed.

An assessment of thyroid Storm in cardiac failure with intrauterine foetal death to rule out anaemia was made. She was identified as a high risk case and potential maternal mortality requiring multi-disciplinary approach and proactive efforts.

She was resuscitated with Oxygen by face mask, she was $100 \mathrm{mg}$ of Pentazocine for analgesia, catheterized to monitor urine output, had a large bore cannula passed and placed on prophylactic parenteral antibiotics. She was commenced on Frusemide, Propranolol and carbimazole and nursed in Fowlers (cardiac) position Consult was sent to endocrinologist, anaesthesist and paediatrician to co-manage her with the Obstetricians. The contractions abated and she became calm and less dyspneic within the first six hours of admission.

Results of Investigations revealed PCV of $26 \%$, Urea, Electrolytes, creatinine and liver function tests were within normal. Her Blood group was A-positive and 2 units of fresh blood was cross-matched. Full blood count and platelets were normal and no malaria parasites seen on blood films. Erythrocyte Sedimentation Rate (ESR) was $20 \mathrm{~mm} /$ hour and bedside clotting time was 4 minutes. Urine analysis revealed trace of protein and there was no glycosuria. The Thyroid function tests indicated raised T3 and T4 (9.3 and 300nmol/L 
respectively) while the Thyroid Stimulating Hormone (TSH) was normal $(0.6 \mathrm{mU} / \mathrm{L})$. Electrocardiography (ECG) showed features of left ventricular hypertrophy and left atrial enlargement. Ultrasound scan confirmed Intrauterine Foetal Death (IUFD) with presence of collapse of the foetal skull bones (Spalding's sign). Echocardiography and chest X - ray were deferred till she was more stable.

She was transfused with 2 units of packed cells over 2 days under Frusemide cover. The endocrinologist and physicians upheld line of management and added tablets Digoxin $0.125 \mathrm{mg}$ daily after the anaemia had been corrected. Her general condition had improved within 48 hours of admission, and she subsequently having strong contractions and was assessed to be in established labour. She was admitted into the labour ward and partograph was used for monitoring the events of labour. The membranes were not ruptured since there was IUFD already. She had one on one nursing care by the senior obstetrician and co-managing consultants were informed.

She was nursed in Fowler's position and received analgesia, antibiotics, oxygen as well as her outlined antithyroid and anti-hypertensive drugs. Fluid use was very judicious to forestall volume overload that would aggravate the cardiac failure. The Nevelli - Barnes forceps were prepared for elective shortening of the second stage. She progressed well in labour and 3 hours after admission into labour ward she was fully dilated. She was discouraged from bearing down. She was placed in lithotomy position, cleaned and draped. The bladder and rectum were emptied and pelvic examination findings confirmed to be optimal for forceps delivery. Standard forceps delivery using the Neville Barnes forceps was performed and she was delivered of a macerated stillborn male that weighed $1.4 \mathrm{~kg}$. . She received Oxytocin injections to aid delivery of the placenta and forestall postpartum haemorrhage but ergometrine was withheld. There were no obvious congenital foetal malformations observed and the placenta was delivered without problems and found to be complete. She received oxytocin and the episiotomy that was given was repaired and she was transferred back to the Intensive care unit for close observation. She continued her drugs and was seen by all teams daily. The Symptoms of toxicity and failure gradually abated and repeat thyroid function test parameters were improving and she was moved out of the ICU.

She was weaned off digoxin and the antihypertensive drugs when the BP and pulse normalized but was maintained on Propranolol and carbimazole. In view of the social issues related to this case, the social workers and Reproductive Health Nurses from Family Planning Clinic reviewed and counseled her. She was discharged to the endocrine and postnatal clinics for follow up. She spent total of nine days on admission.

\section{Discussion}

Miss J.S. had a very turbulent pregnancy that as well posed a challenge to the attending obstetrician and other clinicians in view of the Thyroid storm, cardiac failure and intrauterine foetal death all in a teenager who was unsupported and had suboptimal health seeking behaviour. Pregnancy in these kinds of patients should ideally be embarked upon in collaboration with the health care providers and preconception care should have been offered as this woman had a background endocrinopathy with cardiac involvement ${ }^{7}$. However with the vicious cycle of poverty, illiteracy and disease, in the face of unplanned pregnancy, this patient was unable to benefit from antenatal care whose overall aim is safe motherhood and delivery of healthy offspring ${ }^{3}$. She was an adolescent with little family support carrying a pregnancy she did not anticipate or plan for.

The degree of functional disability according to the New York Heart Classification put Mrs. J.S. in grade IV, since she had symptoms at rest ${ }^{3}$. This is the most severe grade and must be co-managed with the physicians/cardiologists in hospitals to reduce mortality ${ }^{3}$. Mrs. J.S. had a multidisciplinary management as she had social, medical, endocrine, obstetrics and financial problems, all of this were in the aim of forestalling a very potential maternal mortality. The perinatal mortality had already occurred ahead of her arrival in hospital.

Anaemia and infections aggravate heart failure and were sought and managed aggressively ${ }^{3}$, but cautiously to avoid further volume overload. Analgesia, antibiotics, oxygen therapy, positioning and judicious fluid management are paramount in the management of these patients ${ }^{3,8}$ and the second stage was shortened with forceps to forestall further cardiac strain and potential worsening of failure ${ }^{6}$. Follow up by all teams is important in this kind of patient, to ensure control of the hyperthyroid stage and cardiac disease/cardiac failure. Pregnancy is very hazardous in these kinds of patients, with poor perinatal and maternal outcome as occurred in this case with the foetus. Contraception, poverty eradication and women empowerment, among others, however remains paramount in achievement of optimal reproductive health ${ }^{9}$ and there is need to focus on adolescent Health services especially as relates to issues of contraception and pregnancy in this age group.

It is known that women who survive life-threatening complications of pregnancy and childbirth have many similarities with those who die of such complications. This led to the development of the near-miss concept in maternal health. Evaluation of "near-miss" maternal mortality is a robust surveillance method to assess the quality of obstetric care and determinants of poor maternal outcome for improvement of maternity care programs. The WHO set up a working group which reached consensus on defining maternal near miss - "a woman who nearly died but survived a complication that occurred during pregnancy, childbirth or within 42 days of termination of pregnancy". Signs of organ dysfunction that follow life-threatening conditions are used to identify maternal near misses so that the same classification of underlying causes is used for both maternal deaths and near misses. This consistency and a set of nearmiss indicators enables assessments of the quality of care 
provided to pregnant women. ${ }^{10}$ Information about quality and performance of care and the use of critical interventions are useful for strengthening health systems towards Millennium Development Goals 4 and 5. ${ }^{10}$

Small et al examined patient characteristics and outcomes for an obstetric population admitted to intensive care units (ICUs) in a tertiary care center and data of 86 women were analysed. Mean maternal age was $29.8 \pm 7.2$ years and black women were more likely to be admitted to the ICU. The leading reason for admission to the ICUs was maternal cardiac disease $(36 \%)$ followed by complications from hemorrhage (29\%), sepsis (9\%), and hypertensive disorders (9\%). ${ }^{11}$ Another review of 82 studies from 46 countries indicated that prevalence rates varied between $0.6-14.98 \%$ for diseasespecific criteria, $0.04-4.54 \%$ for management-based criteria and $0.14-0.92 \%$ for organ-based dysfunction based on Mantel criteria. The rates are higher in low-income and middle-income countries of Asia and Africa. ${ }^{12}$ A retrospective review in a maternity hospital reviewed women who had required critical (Intensive Unit) care for a 14 year period 1980 to 1993 . There were 76,119 deliveries with two maternal deaths $(2-6 / 100,000)$ Fifty-five women required critical care $(0.7 / 1000)$, mainly for hypertensive disease $(25 \%)$, haemorrhage $(22 \%)$ and sepsis $(15 \%)$. Intensive care was required by $80 \%$, and twenty different specialist groups were consulted. The 55 patients spent 280 days in critical care and 464 days hospital after-care (mean 13 days, range 3-92). ${ }^{13}$

A prospective study in Iran assessed severe maternal morbidity (SMM) based on organ failure criteria from patients admitted in two hospitals from 2009 - 2010. There were 12,149 deliveries, eight maternal deaths and $226 \mathrm{SMM}$ cases. This revealed SMMR of 18.6/1000 live births, MMR of $65.8 / 100000$ live births, and case fatality ratio of $1 / 28$ or $3.5 \%$. Severe preeclampsia and hemolysis elevated liver enzymes low platelet count syndrome (HELLP) (38\%), hemorrhage (23\%) and ectopic pregnancy (14\%) were the top causes of SMM. Similar to HELLP syndrome (25\%) hemorrhage $(25 \%)$, sepsis $(25 \%)$ was the commonest cause of mortality; $39 \%$ of patients were referred from primary or secondary health care units; and $85 \%$ needed intensive care unit admissions. These studies indicate SMM analysis provides valuable information on obstetric care and every SMM could progress to maternal mortality if is not suspected, diagnosed and managed on its golden time 14

A study was also carried out to assess SMM and near miss (NM) cases among adolescent girls and women over 35 years of age in the Brazilian Network for Surveillance of Severe Maternal Morbidity, compared to pregnant women aged 20 to 34 years. A cross-sectional multicenter study conducted in 27 referral obstetric units identified cases of maternal death (MD), NM and other SMM. Among SMM and MD cases identified, the proportion of adolescent girls and older women were $17 \%$ each. Maternal near miss ratio and maternal mortality ratios increased with age, but these ratios were also higher among adolescents aged 10 to 14, although the absolute numbers were low. SMM was high among women below 14 years of age and increased with age in
Brazilian pregnant women. ${ }^{15}$

All of these studies did not indicate that Thyroid storm was found to feature prominently or contributory to the SMM and indicate that such rare conditions must be recognized early to forestall a mortality.

The World Health Organization recently published criteria based on markers of management and of clinical and organ dysfunction which would enable data collection and development of summary estimates but indicate that different approaches are needed to lower the rates of near miss cases ${ }^{16}$ This case had adverse social contributions from being a teenage pregnancy, the prevention of which Centre for Disease Control and Prevention (CDC's) has as one among six top health priorities for youths. Evidence-based teen pregnancy prevention programs should address specific protective factors on the basis of knowledge, skills, beliefs, or attitudes related to teen pregnancy, HIV, values about sex, abstinence and sex partners reduction through access to youth-friendly services. Parents and other trusted adults must play important roles to help teens make healthy choices about relationships, sex, and birth control. ${ }^{17}$ This will help reduce adolescence pregnancy and adverse contributions to Maternal/perinatal morbidity/mortality, considering that Nigeria's MMR is far from that recommended by the MDGs, whose MMR of 630 per 100,000 live births (2010), is one of the top 13 highest MMR worldwide. ${ }^{18}$

\section{Reference}

[1] Seffah J.D. Thyroid diseases in pregnancy. In: Kwawukume E.Y., Emuveyan E.E. (Ed), Comprehensive obstetrics, Asante and Hittscher Printing Press Limited. 2002; 317-320.

[2] Oakley C.M. Heart disease in pregnancy. In: Edmonds K (Ed), Dewhursts Textbook of Obstetrics and Gynaecology, $6^{\text {th }}$ Edition Blackwell Science. 1999;186-196.

[3] Madhusmita Misra, Abhay Singhal, Deborah E Campbell, Phyllis W Speiser, Mary L Windle, Lynne Lipton Levitsky, Merrily P M Poth, Stephen Kemp. Thyroid Storm. MedscapeDrugs and Diseases. Available at http://emedicine.medscape.com/article/925147-overview

[4] Bahn RS, Burch HB, Cooper DS, Garber JR, Greenlee MC, Klein I, Laurberg P, McDougall IR, Montori VM, Rivkees SA, Ross DS, Sosa JA, Stan MN; Thyroid storm. Hyperthyroidism and other causes of thyrotoxicosis: management guidelines of the American Thyroid Association and American Association of Clinical Endocrinologists. Medline Plus.NIH.US National Library of Medicine.Endocr Pract. 2011;17(3):456-520. Available at http://www.nlm.nih.gov/medlineplus/ency/article/000400.htm\

[5] Burch HB, Wartofsky L.Life-threatening thyrotoxicosis. Thyroid storm. Endocrinology and Metabolism Clinics of North America [1993, 22(2):263-277] (PMID:8325286) Available at http://europepmc.org/abstract/med/8325286

[6] WHO. Maternal, newborn, child and adolescent health. Adolescent pregnancy. Available at http://www.who.int/maternal child adolescent/topics/materna l/adolescent_pregnancy/en/ 
[7] Omigbodun A.O. Preconception care in Nigeria: Prospects and constraints. Archives of Ibadan Medicine 2002; 3(1):3-5.

[8] Addo V.N., Arthur G.A. Cardiac disease in pregnancy. In: Kwawukume E.Y, Emuveyan E.E. (Ed), Comprehensive Obstetrics, Asante and Hittscher Printing Press Limited 2002; $268-272$.

[9] Runsewe - Abiodun I, Sule - Odu A.O. Review of the effects of poverty on reproductive health in developing countries. Nigerian Medical Practitioner 2002; 41 (5/6): 60 - 64.

[10] Robert P, Lale S, João P S, Nynke van den B, Cleone R \& on behalf of the WHO Working Group on Maternal Mortality and Morbidity Classifications. WHO maternal death and near-miss classifications. Bulletin of the World Health Organization 2009; 87:734-734. doi: 10.2471/BLT.09.071001

[11] Small MJ, James AH, Kershaw T, Thames B, Gunatilake R, Brown H. Near-miss maternal mortality: cardiac dysfunction as the principal cause of obstetric intensive care unit admissions. Obstet Gynecol 2012; 119(2 Pt 1):250-5. doi:10.1097/AOG.0b013e31824265c7.

[12] Tuncalp O, Hindin MJ, Souza JP, Chou D, Say L. The prevalence of maternal near miss: a systematic review. JOG: An International Journal of Obstetrics \& Gynaecology. Volume 119, Issue 6, Article first published online: 10 APR 2012. Available http://onlinelibrary.wiley.com/doi/10.1111/j.14710528.2012.03294.x/pdf

[13] Baskett FT, Sternadel J. Maternal intensive care and near-miss mortality in obstetrics. British Journal of Obstetrics and Gynaecology. September 1998, Vol. 105, pp. 981-984

[14] Mahvash Zargar 1,*; Javad Marfou 1; Azam Afrakhteh 1; Nahal Nasehi. Severe Maternal Morbidity and Near Misses in Two Tertiary Referral Hospitals in Iran. Jentashapir J Health Res. 2015 April; 6(2): e25886. DOI: 0.5812/jjhr.6(2)2015.25886 Published online 2015 April 25.

[15] Fernando César Oliveira, Fernanda Garanhani Surita, João Luiz Pinto e Silva, José Guilherme Cecatti, Mary Angela Parpinelli, Samira M Haddad, Maria Laura Costa, Rodolfo Carvalho Pacagnella, Maria Helena Sousa, João Paulo Souza and The Brazilian Network for Surveillance of Severe Maternal Morbidity Study Group. Severe maternal morbidity and maternal near miss in the extremes of reproductive age: results from a national cross- sectional multicenter study. BMC Pregnancy and Childbirth. Maternal health and pregnancy. Volume 14 Available at http://www.biomedcentral.com/1471-2393/14/77

[16] Tunçalp O, Hindin MJ, Souza JP, Chou D, Say L. The prevalence of maternal near miss: a systematic review. BJOG. 2012; 119(6):653-61. doi: 10.1111/j.1471-0528.2012.03294.x.

[17] Centers for Disease Control and Prevention. Reproductive Health: Teen Pregnancy. Available at http://www.cdc.gov/teenpregnancy/about/index.htm

[18] Antor ON. Informed community participation is essential to reducing Maternal mortality in Nigeria. Int J Health Psychol Res 2014; 2(1):26 -33. 